\title{
Green Synthesis of Silver - Soil Nanocomposite from Two Different Sources and Its Application for the Removal of Dye Solution
}

\author{
Moumita Sharma, Dr Papita Das, Prof. Siddhartha Datta \\ Department of Chemical Engineering, Jadavpur University, Kolkata 32 \\ Email: moumitasharma21@gmail.com; papitasaha@gmail.com
}

\begin{abstract}
In this paper a comparative study had been performed by green synthesis of silver nanocomposites using neem leaf extract (Azadirachta indica) and basil leaf extract (Ocimum sanctum). The green synthesis of silver nanocomposites (soil-AgNP) was used since it is efficient as well as cost effective. The nanocomposites were characterized by color change, UV-VIS Spectroscopy, XRD (X-Ray Diffraction Analysis), SEM (Scanning Electron Microscopic Analysis), FTIR (Fourier Transform Infrared Spectroscopic Analysis) and TEM (Transmission Electron Microscopic Analysis). Change in the color of the solution of leaf extract and silver nitrate to dark brown corresponds to the Plasmon absorbance of the silver nanoparticles. The SEM, TEM and FTIR studies also confirmed the formation of silver nanocomposites. Various experiments were carried out by varying the properties like adsorbent dose, time, temperature, shaker speed, $\mathrm{pH}$ and concentration. Adsorption isotherms, thermodynamics and kinetics were also evaluated. It was noticed that the silver nanocomposite from basil leaf was providing around $98 \%$ removal of Gentian Violet dye which was relatively higher than both neem leaf composite as well as soil.
\end{abstract}

Keywords: Silver nanoparticles (AgNP), silver nanocomposites (AgNP-Soil), gentian violet dye $(\mathrm{GV})$, basil (ocimum sanctum), neem (azadirachta indica), percentage removal, isotherms, kinetics.

\section{Highlights}

- Green synthesis of silver nanocomposites using neem leaf extract (Azadirachta indica) and basil leaf extract (Ocimum sanctum).

- Silver nanocomposites (soil-AgNP) was used since it is efficient, nonhazardous as well as cost effective.

- Characterization showed the morphology and chemical composition of silver nanocomposites.

- Silver nanocomposite from basil leaf (O. sanctum) was providing around $99.4 \%$ removal of Gentian Violet, $98.1 \%$ for silver nanocomposite made of neem leaf (A. indica) and $97.4 \%$ for soil.

\section{Introduction}

The dyes in their synthetic form are widely available in the effluents of industries viz - textiles, tanning, leather, food processing, cosmetics, paper and pulp etc. There are aromatics rings as well as other complex substances in the dyes which make them carcinogenic and mutagenic that is harmful for all the living organisms [Sun et al., 2014]. When they come in contact with water they reduce the light penetration capacity in water which hinders photosynthetic activities in aqueous system. They can also cause chelation of the metal ions causing microtoxicity in fish and other living organisms. This continuous discharge of the dyes as effluents has become a highly distressing issue which is threatening the safety of water bodies as well as environment. Many physical, chemical [Gholivand et al., 2015; Zinadini et al., 2014; Evangelin Femila et al., 2014] and biological processes [Natarajan et al., 2010; Saha et al., 2011; Wang et al., 2008; Khataee et al., 2011; Mouxhg et al., 2006] were considered for the removal of these dyes from effluents but most of them are costly and not very effective.

Nanotechnology has gained great height with potential application in many fields from electronics, preservatives, medicine to cosmetics. It has unlocked paths for many brisk growing industries among 
which pollution control in waste water effluents is significant [Pandian et al., 2015]. Silver nanopaticles has acquired acclamation for its wide range of applications like sensors, optics, preservatives, electronics and even medicine (sterilizers, disinfectant, antimicrobials etc) [Prabhu et al., 2012]. There are many ways of production of silver nanoparticles among which green synthesis or synthesis using plant extracts is the most easy, economic and less time and energy consuming technique. The green synthesis can be done using many plant parts - leaf, seeds [Dhand et al., 2016], barks [Ahmad, 2009], buds, peels [Saeed et al., 2010], mesocarps [Mariselvam et al., 2014], roots, tubers [Sadhegi et al., 2015], fruits [Moghaddam et al., 2014] and even flowers [Senthilkumaar et al., 2006]. Experiments were performed by many scientists, researchers, universities and laboratories on the green synthesis of various metal nanocomposites like silver $(\mathrm{Ag})$, gold $(\mathrm{Au})$ [Patra et al., 2015], copper $(\mathrm{Cu})$, Nickel $(\mathrm{Ni})$, Chromium $(\mathrm{Cr})$ [Hossain et al., 2005] etc from various plant parts viz - Croton sparsiflorus morong leaf extract [Kathiravan et al., 2015], Alternanthera dentata leaf extract [Kumar et al., 2014], Azadirachta indica leaf extract [Satapathy et al., 2013], Ocimum sanctcum leaf extract [Pandian et al., 2015], Eucalyptus oleosa leaf extract [Pourmortazavi et al.,2015], Artocarpus heterophyllus (jackfruit) leaf extract [Saha et al., 2012], Eucalyptus chapmaniana leaf extract [Sulaiman et al., 2013], Ulva lactuca (seaweed) [Kumar et al., 2013] etc but comparative studies checking the effectiveness of a better adsorbent are very few. In our comparative study we are using the leaf extracts of basil plant (Ocimum sanctum) and neem (Azadirachta indica) for the preparation of the silver nanocomposites. Basil and Neem leaves are considered because they are famous as ayurvedic herbs having antiseptic, antibiotic and antimicrobial properties. Characterization of the composites were also done using SEM, TEM, XRD, FTIR and UVVIS Spectroscopy. The formed two silver nanocomposites and soil were then used for various experiments for the removal of the dye Gentian Violet. The results obtained were plotted in graphs and compared. It is observed that out of the three adsorbents, the silver nanocomposite made of basil leaf extract is showing the maximum percentage removal of about $99.4 \%$.

\section{Materials and Methodology}

\section{$2.1 \quad$ Materials}

The leaves of neem (Azadirachta indica) and Basil (Ocimum sanctum) were obtained from Sonarpur area of Kolkata, West Bengal. Particularly these two leaves were considered because of their high bactericidal and fungicidal activities and both of them are well considered as ayurvedic herbs which act as tonic, astringent and antiseptics. The soil required for the synthesis of nanocomposite was also collected from the same area. Silver nitrate $\left(\mathrm{AgNO}_{3}\right)$ and the dye Gentian Violet (GV) required were bought from Merck Company (Germany).

\subsection{Methodology}

The methodology is briefly described in four steps. They are

- Collection of the leaves and preparation of the leaf extracts.

- Leaf extract mediated synthesis of the silver nanoparticles.

- Preparation of silver nanocomposite and

- Preparation of dye stock solution.

\subsubsection{Collection of the Leaves and Preparation of Leaf Extracts}

The fresh and healthy leaves of neem $(A$. indica) and basil/tulasi $(O$. sanctum) were collected separately. Then they were washed thoroughly thrice using double distilled water. After that the washed leaves were chopped into fine pieces using sterilized knife. About 10 grams of chopped leaves of both neem and basil were then taken separately in two $250 \mathrm{ml}$ beaker and $100 \mathrm{ml}$ of double distilled water was added to both of them and boiled for 15- 20 minutes. The two pale green color solutions obtained were allowed to cool and filtered using filter paper. These pale green solutions were the required leaf extracts which act as the reducing agent. The solution was sealed tightly and placed in 4 degree Celsius for further use.

\subsubsection{Leaf Extract Mediated Synthesis of the Silver Nanoparticles}

$1 \mathrm{mM}$ of silver nitrate solution was prepared. Then $95 \mathrm{ml}$ of silver nitrate solution was taken in two 250 $\mathrm{ml}$ Erlenmeyer flasks and $5 \mathrm{ml}$ of the leaf extracts of neem and basil were added to both the flasks 
separately. For the complete bioreduction of the solution they were placed in a microwave oven at $300 \mathrm{~W}$ for 10 minutes. A color change was observed from pale green to pale red and at the end to dark reddish brown. After that the solutions are measured in a UV-VIS Spectrophotometer. Then the colloidal mixture obtained was kept for future use.

\subsubsection{Preparation of Silver Nanocomposites}

Soil needed for the preparation of the silver nanocomposites was first collected, dried and churned into fine particles. Now both the silver nanoparticles containing colloidal mixture were added to it separately and mixed properly. The solution mixtures are placed in an incubator shaker overnight. After the completion of about 12 hours the solutions were taken out and allowed to settle for another 12 hours. The supernatant obtained was therefore removed and the settled composites were dried again, churned into fine particles and sieved. Thus two nanocomposites were obtained which act as the required adsorbent.

\subsubsection{Preparation of Dye Stock Solution}

Gentian Violet (GV) dye having molecular weight 408, molecular formula $\mathrm{C} 25 \mathrm{H} 30 \mathrm{~N} 3 \mathrm{Cl}$ and maximum absorption peak $\lambda$ max 578nm was bought from Merck Company (Germany). The solid dye was then added to double distilled water to get the required stock solution. Now different concentrations were obtained by diluting the stock solution. The $\mathrm{pH}$ concentration can be altered by adding $0.1 \mathrm{~N} \mathrm{HCl}$ and $0.1 \mathrm{~N} \mathrm{NaOH}$ solution.

\subsection{Characterization of the Nanocomposites Formed}

The following analyses were performed for the three adsorbents - two nano adsorbents made of O. sanctum and A. indica leaf extracts and soil.

\subsubsection{UV-VIS Spectroscopy Analysis}

During the synthesis of silver nanoparticles from the leaf extract and silver nitrate solution, a change in color was obtained from pale green to pale red and at last dark reddish brown. The UV-VIS Spectroscopy Analysis of the colloidal mixture was done in a UV-visible spectrophotometer (Lambda 25 UV-Vis Spectrophotometer Perkin Elmer). Furthermore the batch studies were also conducted using the UV-visible spectrophotometer.

\subsubsection{Scanning Electron Microscopy}

The size and the morphological exams on the silver nanoparticles formed in the composites were determined using SEM. The samples were coated with a thin layer of gold for making them conductive and microscopic analyses were performed using Scanning electron Microscope (Model Hitachi S-3000N).

\subsubsection{Fourier Transform Infrared Spectroscopic Analysis}

Presence of different functional groups in the three composites were measured by using the FTIR Analysis since each group has a specific energy absorption band. So the analysis for the three components were done in a FTIR Spectrophotometer (Perkin-Elmer Spectrum version 10.4.4 model) in a wavelength range of 4000-400 cm-1.

\subsubsection{X-Ray Diffraction (XRD) Analysis}

The X-ray diffraction analysis of the nanocomposite adsorbent was carried out using X-ray diffractomet er equipment with a $\mathrm{Cu} \mathrm{K}$ a radiation source and Braggs angle ranging from 20 -80 degrees for the three adsorbents to find out the crystalline nature of the three composites. Generally crystals are regular arrays of atoms, and X-rays are considered waves of dectromagnetic radiation. The atoms scatter X-ray waves, as a result an X-ray striking an electron generates secondary round waves ejected by the electron.

\subsection{Batch Studies}

Few batch studies were carried out in 250-mL Erlenmeyer flasks with $100 \mathrm{~mL}$ of dye solution. A weighed amount $(100 \mathrm{mg})$ of two nanocomposites and soil were added separately to the dye solution in separate flasks. The flasks were agitated at a speed of $140 \mathrm{rpm}$ in an incubator shaker at $308 \mathrm{~K}$. The influence of $\mathrm{pH}$ (2.0-10.0), initial dye concentration (100-500 mg L-1), nanocomposite dosage (0.025-0.2 g L-1) and temperatures $(298,303,310,313,318 \mathrm{~K})$ were evaluated. At regular time intervals samples were collected for measuring the residual dye concentration in the solutions. The residual amount of dye in 
each flask was explored using UV/VIS spectrophotometer (Lambda 25 UV-VIS Spectrophotometer Perkin Elmer). The amount of dye adsorbed per unit of composites for all three of the adsorbents were determined according to a mass balance equation.

$$
q_{e}=\frac{\left(c_{i}-c_{e}\right) V}{m}
$$

where $\mathrm{C}_{\mathrm{i}}$ is the initial dye concentration $\left(\mathrm{mg} \mathrm{L}^{-1}\right), \mathrm{C}_{\mathrm{e}}$ is the equilibrium dye concentration in solution $\left(\mathrm{mg} \mathrm{L}^{-1}\right), \mathrm{V}$ depicts the volume of the solution $(\mathrm{L})$, and $\mathrm{m}$ represents the mass of the nanocomposite in $\mathrm{g}$.

The percent removal (\%) of dye was investigated using the following equation:

$$
\left\{\frac{\left(C_{i}-C_{e}\right)}{C_{i}}\right\} * 100
$$

The result obtained showing the effects of parameters were compared for the three adsorbent used and plotted in form of graphs.

\subsection{Adsorption Studies}

The mechanism of adsorption process is well understood by equilibrium concentration in aqueous solutions. To find out the relationship between amount of adsorbate $\left(\mathrm{q}_{\mathrm{e}}\right)$ and its concentration in aqueous phase $\left(\mathrm{C}_{\mathrm{e}}\right)$ three isotherm models are fitted - Langmuir [Langmuir,1916], Freundlich [Freundlich,1906] and Temkin using datas from various time intervals for the three adsorbents.

\subsection{Kinetics Studies}

Kinetics studies determine the rate of adsorption which is an important parameter to find out the amount of adsorbate removed from the solution. Lagergren's pseudo- first- order kinetics and Ho and McKay's pseudo- second- order kinetic models [Ho and McKay,1999] were utilized to find out the kinetics of the three adsorbents and the results were compared.

\section{Results and Discussion}

In the solutions of $1 \mathrm{mM}$ silver nitrate along with aqueous extract of the A. indica and O. sanctum leaf samples the formation of AgNPs were confirmed by change in the color to dark reddish brown which may be due to excitation of Plasmon vibrations shown in figure $1 \mathrm{~A}$.

The synthesis of Ag nanoparticles in aqueous extracts were identified by collecting the samples and measuring using UV-VIS spectrophotometer. For the nanocomposite made of basil leaf the peak absorption is obtained at $422 \mathrm{~nm}$ and for neem leaf the value is $435 \mathrm{~nm}$ shown in figure $1 \mathrm{~B}(\mathrm{~A})$ and $1 \mathrm{~B}$ (B).

The SEM images of the three adsorbents (soil-AgNP from O. sanctum and A. indica and soil) shown in the figure $1 \mathrm{C}(\mathrm{A}), 1 \mathrm{C}(\mathrm{B})$ and $1 \mathrm{C}(\mathrm{C})$ indicated that the soil showed a crystalline mass form and the shape of silver nanoparticles were spherical, oval and irregular polygonal for both the adsorbents made of neem and basil leaf extracts.

The TEM image of the soil-AgNP from O. sanctum and A. indica were also provided in figure 1D (A) and $1 \mathrm{D}(\mathrm{B})$. The morphology of the silver nanoparticles formed were quite spherical and the size ranges around $50 \mathrm{~nm}$ which was quite a match to the previous reports.

Fourier Transform Infrared spectral analysis performed for the three adsorbents, showed range of absorbance bands in 400-4,000 $\mathrm{cm}^{-1}$ shown in figure 1E. The peaks of the absorption bands for adsorbent made of basil leaf were at 519.08, 692.84, 777.09, 1,633.93 and 3,617.57 $\mathrm{cm}^{-1}$ which were used for the identification of the functional groups present in the aqueous AgNPs. The peaks of the absorption bands for adsorbent soil were at $693.41,776.40$ and $986.99 \mathrm{~cm}^{-1}$ The peaks of the absorption bands for adsorbent made of neem leaf were at $721,1,637.27,2,364.3,3,334.1$ and $3,745.08 \mathrm{~cm}^{-1}$. These bands were mainly due to the presence of alkane, amide, alkene, chloride, carboxyl group, free alcohol, aromatic ring, hydroxyl group, aldehyde and carbonyl group present in the samples. 


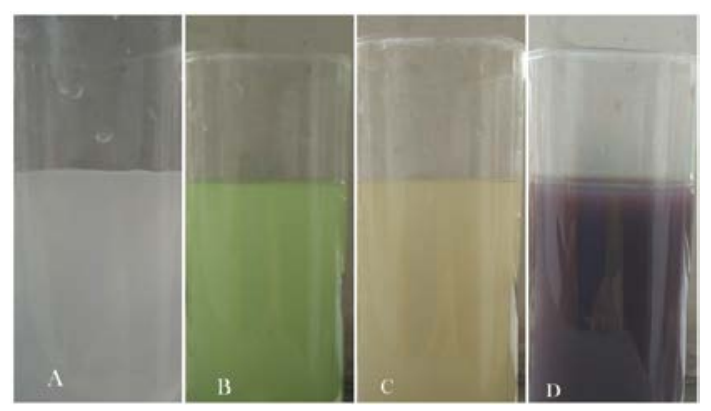

Figure: 1A depicts the color change observed. [A represents the $\mathrm{AgNO}_{3}$ solution, B depicts the O. sanctum leaf extract, $\mathrm{C}$ depicts $O$. sanctum leaf extract and $\mathrm{AgNO}_{3}$ solution and D depicts the AgNP formed ].
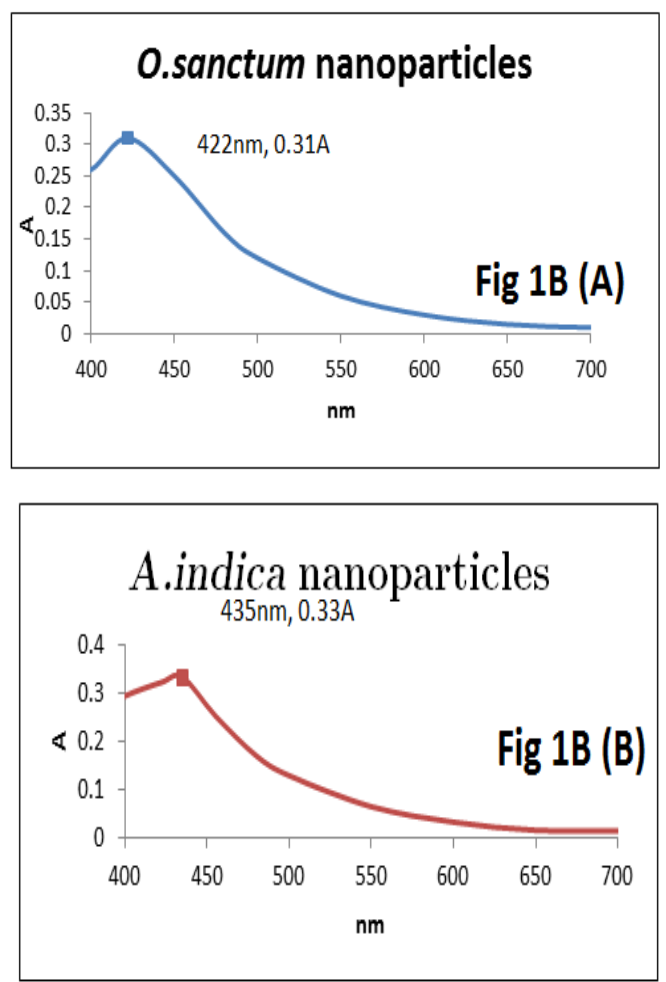

Figure: 1B represents the UV-VIS Spectroscopy diagram of AgNP formed from A. indica (A) and O. sanctum (B) respectively.

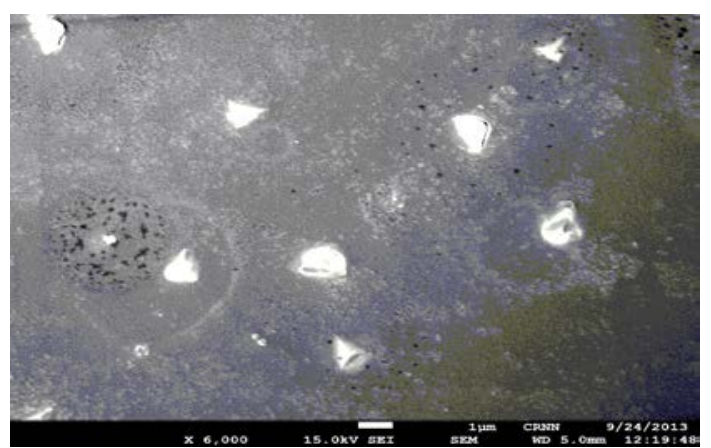

Fig 1C(A) 


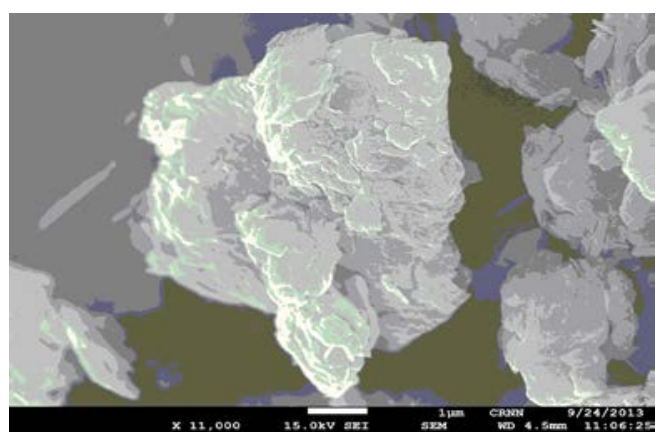

Fig $1 \mathrm{C}(\mathrm{B})$

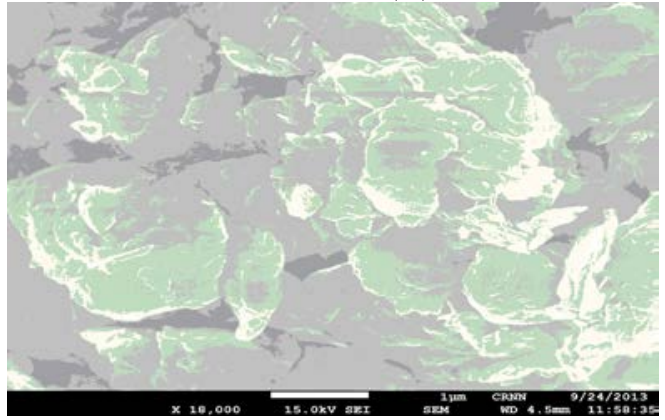

Fig $1 \mathrm{C}(\mathrm{C})$

Figure: 1C represents the SEM image of A.indica leaf extract containing nanocomposite (A), O. sanctum leaf extract containing nanocomposite (B) and soil (C) respectively.

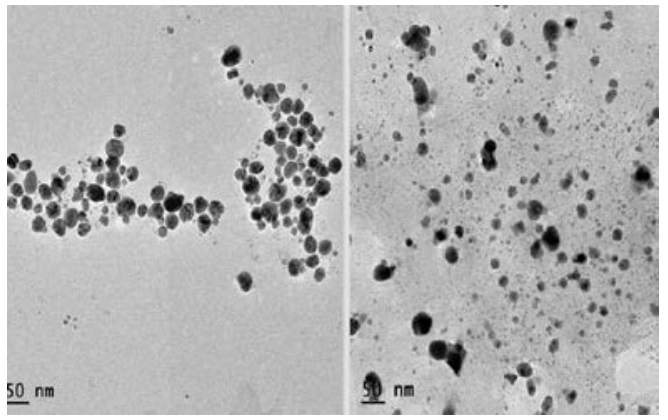

Fig 1D (A and B)

Figure: 1D represents the TEM image of $O$. sanctum leaf extract containing nanocomposite (A) and $A$. indica leaf extract containing nanocomposite (B) respectively.

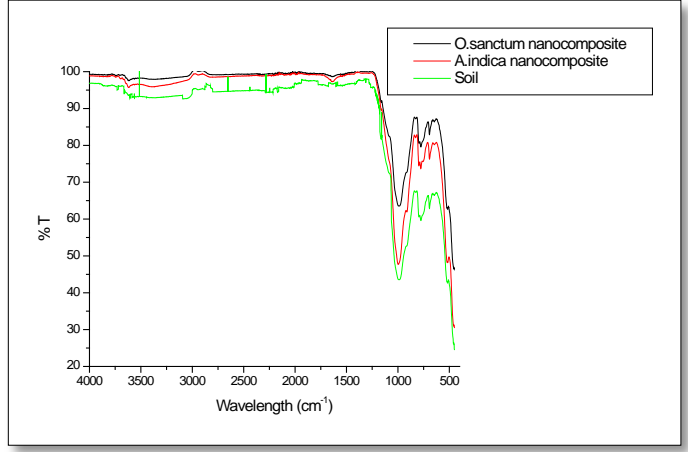

Fig $1 \mathrm{E}$

Figure: 1E represents the FTIR image of the three adsorbents. 
XRD analysis of Ag-nanocomposite form A. indica and O. sanctum leaf extracts and only Soil shown in figure $1 \mathrm{~F}$ demonstrated that major components present in nanocomposite were Silver (Ag) along with minerals like quartz, feldspar, mica, amphibole, kaolinite and calcite due to the presence of soil in the composite.

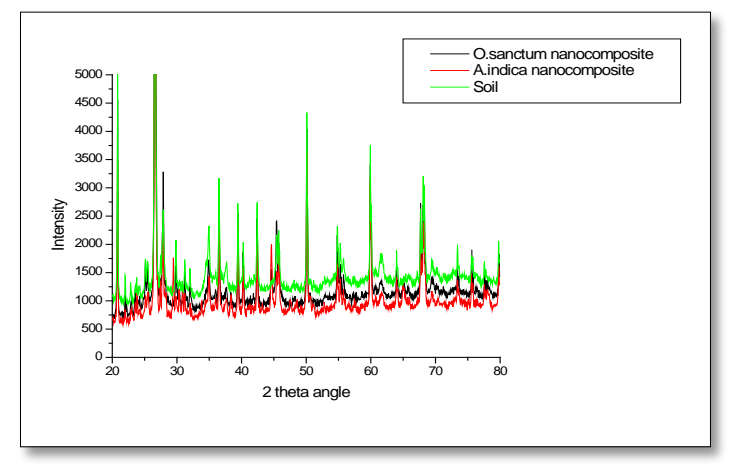

Fig $1 \mathrm{~F}$

Figure: $\mathbf{1 F}$ represents the XRD image of the three adsorbents.

The soil sample used in the experiment had a $\mathrm{pH}$ of 7.4 , moisture content of $27 \%$ and amount of clay present $28 \%$, silt $66 \%$ and sand $5 \%$.

In case of the batch experiments conducted $100 \mathrm{mg}$ of soil, $100 \mathrm{mg}$ of soil-AgNP from A. indica extract and $100 \mathrm{mg}$ of soil-AgNP from O. sanctum extract were taken separately and added to $100 \mathrm{ml}$ of 200ppm Gentian Violet dye solutions in three conical flasks and the effect of the different parameters like Adsorption dose, Concentration of dye, $\mathrm{pH}$, Temperature, Time were evaluated and the results obtained were compared in graphical form.

\subsection{Effect of Mass of Adsorbents}

$100 \mathrm{ml}$ of gentian violet dye of concentration $200 \mathrm{mg} / \mathrm{L}$ were taken in five conical flasks and in them 25mg, 50mg, 75mg, $100 \mathrm{mg}$ and $200 \mathrm{mg}$ of nanocomposite adsorbent made of $O$. sanctum were added separately and placed in a shaker incubator at speed $120 \mathrm{rpm}$. The temperature was maintained at $308 \mathrm{~K}$ throughout the process. Now at a time interval of 2 minutes, 5 minutes, 8 minutes, 12 minutes and 15 minutes samples were taken out, centrifuged at $10000 \mathrm{rpm}$ for 15 minutes and the amount of dye removed from the solution was measured using a spectrophotometer. The same process was carried out for nanocomposites made of $A$. indica and only soil adsorbents and percentage removal was obtained.

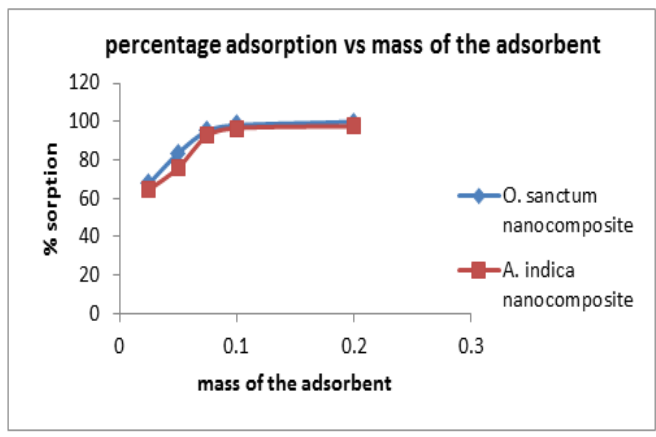

Figure 2. Effect of adsorbent dose.

It was observed from figure- 2 that, with the increase in the adsorbent dosage from $25 \mathrm{mg}$ to $200 \mathrm{mg}$ there was a gradual increase in percentage removal for all the three adsorbents. The percentage removal increased from 67.58 to 99.83 for $O$. sanctum nanocomposite, from 64.34 to 97.67 for $A$. indica and from 
56.27 to 95.89 in case of soil. The reason of this behavior may be due to stipulated area of adsorption and accessibility of more binding sites.

\subsection{Effect of Temperature}

The effect of temperature was obtained for the temperature levels $298 \mathrm{~K}, 303 \mathrm{~K}, 308 \mathrm{~K}, 313 \mathrm{~K}$ and $318 \mathrm{~K}$ respectively for all the three adsorbents at shaker speed $120 \mathrm{rpm}$. In all the three adsorbents, with the increase in temperature, there was an increase in the percentage removal shown in figure 3 . The increasing temperature may be explained by the increased attraction of binding sites with the dye molecules at higher temperature or an increase in motion of the dye molecules which may result in rapid adsorption.

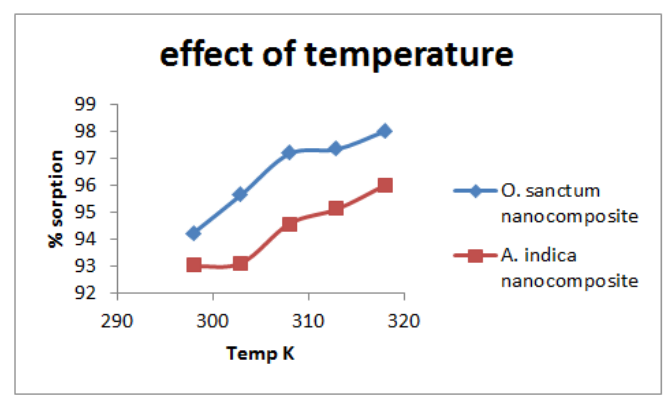

Figure 3. Effect of temperature.

\subsection{Effect of $\mathrm{pH}$}

$\mathrm{PH}$ stability of the nanocomposites were done in a range of $\mathrm{pH} 2$ to 10 having constant temperature $308 \mathrm{~K}$ and shaker speed $120 \mathrm{rpm}$ shown in figure 4. UV- VIS spectrophotometer reading showed that maximum degradation of dyes was obtained at $\mathrm{pH} 2$ for all the three adsorbents from the solutions at $\lambda_{\max }$ value $580 \mathrm{~nm}$.

The GV dye solution had an optimum $\mathrm{pH}$ of 7.2 and the soil-AgNP from $O$. sanctum, A. indica and soil had pH 7.6, 7.8 and 7.4 respectively. In the comparative study the maximum adsorption was showed by the soil-AgNP from O. sanctum which was $98.49 \%$. At lower pH the adsorbents and the cationic dyes exhibit strong columbic repulsion which may be a reason of increased percentage removal.

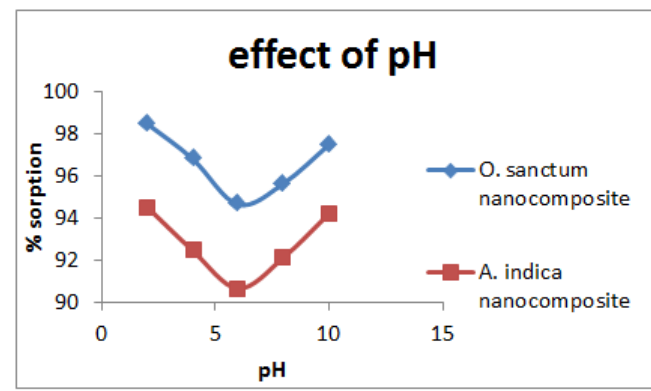

Figure 4. Effect of pH.

\subsection{Effect of Dye Concentration}

The effect of the dye concentration in a range of 100 to $500 \mathrm{mg} \mathrm{L}^{-1}$ for three adsorbents at $308 \mathrm{~K}$ and $\mathrm{pH}$ 2 were shown in the figure 5 . The adsorption process was highly influenced by the initial concentration of the dye (adsorbate). It was observed that until a certain point, the amount of dye adsorbed increased with the increase in dye concentrations after which there was a gradual decrease shown in figure 5. 


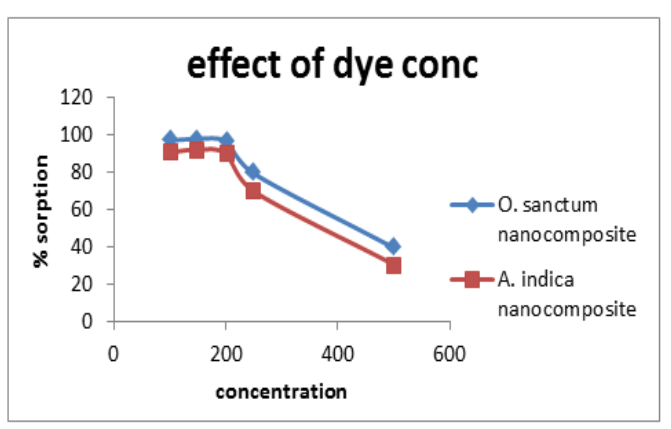

Figure 5. Effect of Dye Concentration.

In the figure it is observed that with increase in dye concentration from 100 to $200 \mathrm{mg} \mathrm{L}^{-1}$ for all the three composites, there was an increase in percentage removal but from concentration 200 to $500 \mathrm{mg} \mathrm{L}^{-1}$ there was a decrease. The increasing trend was presumably due to increase in the driving force and availability of more GV ions near the active sites. But as the equilibrium concentration is reached, the adsorption site in AgNP composites get saturated since there is no available binding sites. As a result excess dye molecules stay in the solution and decrease the percentage of adsorption.

\subsection{Effect of Contact Time and Agitation Speed}

The experiment of contact time was performed for time - 2 minutes, 5 minutes, 8 minutes, 12 minutes, 15 minutes, 30 minutes, 60 minutes, 90 minutes and 120 minutes for $\mathrm{pH}$ 2, temperature $308 \mathrm{~K}$ and 120 rpm. The experiment was performed for soil, soil-AgNP for O.sanctum and soil-AgNP for A.indica. It was observed that the percentage removal keeps on increasing with increase in contact time, but after certain time when it reaches equilibrium there was no further change in the removal. It may be due to the fact that contact time increases the availability of active sites while further increase causes cessation in the movement of the cationic dyes on the silver nanoparticles.

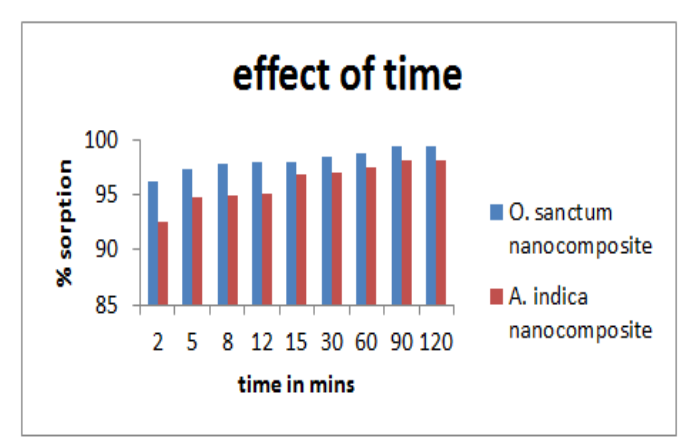

Figure 6. Represents effect of contact time.

Similar trend is obtained for the agitaton speed experiment where with the increase of rpm from 80 to 150 the percentage removal increased from 87.8 to 95 in soil-AgNP from O.sanctum and 84.2 to 92.6 in soil-AgNP from A.indica shown in figure 6 and 7. 


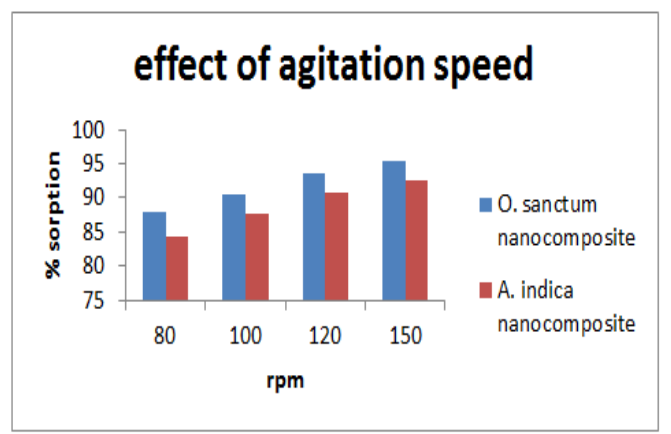

Figure 7. Depicts effect of agitation speed

\subsection{Adsorption Isotherms}

\subsubsection{Langmuir Isotherm}

Adsorption isotherm illustrates the alliance between the adsorbate adsorbed on the surface of adsorbent and concentration of adsorbate in equilibrium at constant temperature. Langmuir isotherm [Langmuir, 1916] is mainly acceptable for a monolayer adsorption onto a surface containing a limited number of identical sites. It is represented by the equation.

$$
\frac{\mathrm{C}_{\mathrm{e}}}{q_{e}}=\frac{C_{e}}{q_{o}}+1 /\left(K_{L} \cdot q_{o}\right)
$$

where $\mathrm{q}_{0}\left(\mathrm{mg} \cdot \mathrm{g}^{-1}\right)$ is the maximum adsorptive capacity and $\mathrm{K}_{\mathrm{L}}\left(\mathrm{L}_{\mathrm{mg}} \mathrm{mg}^{-1}\right)$ denotes the energy of adsorption. The experimental data $\mathrm{c}_{e} / \mathrm{q}_{e}$ were plotted against $\mathrm{c}_{\mathrm{e}}$ for the three nanocomposites at temperature $308 \mathrm{~K}$ and shown in figure 8.

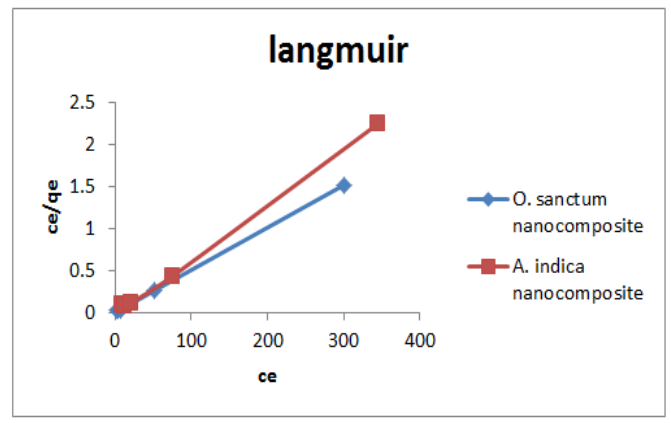

Figure 8. Langmuir isotherm curve for silver nanocomposites from A. indica andO. sanctum.

Value of $\mathrm{q}_{\mathrm{m}}$ and $\mathrm{K}_{\mathrm{L}}$ were determined from the plot. Another important parameter in the Langmuir is the separation factor $R_{L}$ which indicates the nature of isotherm $\left(R_{L}>1\right.$ is considered unfavorable, $R_{L}=1$ is considered linear, $R_{L}=0$ is irreversible and $0<R_{L}<1$ is considered favorable) and is represented by the equation.

$$
R_{L}=1 /\left(1+K_{L} \cdot C_{e}\right)
$$

Parameters and correlations are obtained from the plots of Langmuir provided in the Table 1.

The Langmuir model was well fitted with the value of $\mathrm{R}_{\mathrm{L}}$ between 0 to 1 which indicates a favorable adsorption of adsorbates. Moreover higher correlation coefficient $\left(\mathrm{R}^{2}\right)$ indicated the monolayer adsorption of adsorbate without any interaction in between the adsorbed species. Similar trend was reported by [Pandian et al., 2015] and [Satapathy et al., 2013] for dyes. 
Table 1: The table represents the correlation coefficients and constants of Langmuir Isotherm for three adsorbents.

\begin{tabular}{llll}
\hline LANGMUIR PARAMETERS & Soil-AgNP $($ O.sanctum $)$ & Soil-AgNP $($ A.indica $)$ & soil \\
\hline $\mathrm{q}_{0} \mathrm{mg} / \mathrm{g}$ & 200 & 166.67 & 142.857 \\
\hline $\mathrm{K}_{\mathrm{L}} \mathrm{L} / \mathrm{mg}$ & 1.6667 & 1.5 & 3.57 \\
\hline $\mathrm{R}^{2}$ & 0.999 & 0.998 & 0.996 \\
\hline $\begin{array}{l}\text { FREUNDLICH } \\
\text { PARAMATERS }\end{array}$ & & \\
\hline $\mathrm{K}_{\mathrm{F}} \mathrm{mg} / \mathrm{g}$ & 9.79 & 9.66 & 13.17 \\
\hline $\mathrm{n}$ & 6.25 & 6.54 & 13.89 \\
\hline $\mathrm{R}^{2}$ & 0.858 & 0.863 & 0.796 \\
\hline TEMKIN PARAMETERS & & & \\
\hline $\mathrm{B} \quad \mathrm{J} / \mathrm{mol}$ & 17.78 & 20.9 & 19.58 \\
\hline $\mathrm{B}$ & 144.022 & 122.52 & 130.78 \\
\hline $\mathrm{A} \mathrm{L} / \mathrm{mg}$ & 6.169 & 12.92 & 7.595 \\
\hline $\mathrm{R}^{2}$ & 0.739 & 0.768 & 0.714 \\
\hline
\end{tabular}

\subsubsection{Freundlich Isotherm}

Plots were obtained between $\operatorname{lnc}_{\mathrm{e}}$ and $\operatorname{lnq}_{\mathrm{e}}$ for the three adsorbents and compared (figure not shown) represented by the equation

$$
\ln q_{e}=\ln K_{F}+(1 / n) \ln C_{e}
$$

The estimated coefficients of the Freundlich model $\left(\mathrm{K}_{\mathrm{F}}\right.$ and $\left.\mathrm{n}\right)$ for $\mathrm{GV}$ dye adsorption onto soil and silver nanocomposites were listed in the table 1 below. The $K_{F}$ value represents the degree of adsorption and $\mathrm{n}$ denotes the adsorption intensity. The value of $\mathrm{n}$ was higher than unity for all the adsorbents, indicating that GV ions were favorably adsorbed on silver nanocomposites.

\subsubsection{Temkin Isotherm}

The temkin model is linearly represented as equation

$$
q_{e}=(R T / b) \ln \left(A C_{e}\right)
$$

where A and B are temkin isotherm constant $\left(\mathrm{L}_{\mathrm{g}} \mathrm{g}^{-1}\right)$ and heat of sorption $\left(\mathrm{J} . \mathrm{mol}^{-1}\right)$ respectively. R is the gas constant $\left(\mathrm{J}_{\mathrm{mol}} \mathrm{l}^{-1} \mathrm{k}^{-1}\right), \mathrm{b}$ is the temkin isotherm constant associated to energy parameter B.

The plot is drawn between $\operatorname{lnc}_{\mathrm{e}}$ and $\mathrm{q}_{\mathrm{e}}$ for the three adsorbents (figure not shown) and the correlation parameters and coefficient are given in table 1.

\subsection{Thermodynamic Studies}

To deduce whether the process is spontaneous in nature or not, thermodynamic studies of an adsorption process are essential. Therefore parameters like Gibbs free energy change $\left(\triangle \mathrm{G}^{0}\right)$, enthalpy $\left(\Delta \mathrm{H}^{0}\right)$ and entropy $\left(\triangle S^{0}\right)$ were calculated using Van't Hoff plot to check the feasibility of the process and to confirm the nature of the adsorption process.Similar plots were drawn for the other two adsorbents (figure not shown). The following equations were used:

$$
\begin{gathered}
\Delta \mathrm{G}^{0}=-\mathrm{RT} \ln \mathrm{K}_{\mathrm{C}} \\
\Delta \mathrm{G}^{0}=\Delta \mathrm{H}^{0}-\mathrm{T} \Delta \mathrm{S}^{0}
\end{gathered}
$$

Table 2 shows the values of different thermodynamic parameters obtained. The negative value of $\Delta \mathrm{G}^{0}$ for all the temperatures, for the three adsorbents confirmed that the processes were spontaneous. Negative value of $\Delta \mathrm{H}^{0}$ implied that the adsorption processes were exothermic in nature. The positive value of $\triangle \mathrm{S}^{0}$ indicated the increase in randomness during adsorption. The calculated $\mathrm{E}_{\mathrm{a}}$ value was less than $40 \mathrm{~kJ} \mathrm{~mol}^{-1}$ suggesting that the adsorption process of $\mathrm{GV}$ on nanocomposite followed physical adsorption [Satapathy et al., 2013]. 
Table 2: The table represents the thermodynamic parameters for the nanocomposites made of O. sanctum and A. indica.

\begin{tabular}{lllllllll}
\hline PARAMETERS & $\begin{array}{l}\Delta \mathrm{H}^{0} \mathrm{KJ} \\
\mathrm{mol}^{-1}\end{array}$ & $\begin{array}{l}\Delta \mathrm{S}^{0} \mathrm{~kJ} \\
\mathrm{~mol}^{-1}\end{array}$ & $\begin{array}{l}\Delta \mathrm{G}^{0}\left(25^{0} \mathrm{C}\right) \mathrm{kJ} \\
\mathrm{mol}^{-1}\end{array}$ & $\begin{array}{l}\Delta \mathrm{G}^{0}\left(30^{0} \mathrm{C}\right) \mathrm{kJ} \\
\mathrm{mol}^{-1}\end{array}$ & $\begin{array}{l}\Delta \mathrm{G}^{0}\left(35^{0} \mathrm{C}\right) \mathrm{kJ} \\
\mathrm{mol}^{-1}\end{array}$ & $\begin{array}{l}{ }^{0}\left(40^{0} \mathrm{C}\right) \mathrm{kJ} \\
\mathrm{mol}^{-1}\end{array}$ & $\begin{array}{l}\Delta \mathrm{G}^{0}\left(45^{0} \mathrm{C}\right) \mathrm{kJ} \\
\mathrm{mol}^{-1}\end{array}$ \\
\hline $\begin{array}{l}\text { Soil-AgNP } \\
\text { leaf) }\end{array}$ & (basil & -1.068 & 7.004 & -6.92 & -7.79 & -9.04 & 6 & -10.24 \\
$\begin{array}{l}\text { Soil-AgNP } \\
\text { leaf) }\end{array}$ & (neem & -0.709 & 5.2 & -6.41 & -6.57 & -7.32 & -7.73 & -8.40 \\
\hline
\end{tabular}

\subsection{Kinetic Studies}

Adsorption kinetics study usually portrays the uptake rate of the dye particles and also predicts the residence time of the dye molecules at the solid-liquid interface. The Lagergren's pseudo-first-order and Ho-McKay's pseudo-second-order (Ho and McKay, 1999) models were implemented to the experimental data obtained for the three adsorbents shown in figure 9.

Pseudo-first-order:

$$
\ln \left(q_{e}-q_{t}\right)=\ln q_{e}-K_{1} t / 2.303
$$

Pseudo-second-order:

$$
\frac{t}{q_{t}}=\frac{1}{K_{2} \cdot q_{e}^{2}}+t / q_{e}
$$

The values of pseudo-first-order rate constants, $\mathrm{k}_{1}\left(\mathrm{~min}^{-1}\right)$ and $\mathrm{q}_{\mathrm{e}}\left(\mathrm{g} \cdot \mathrm{mg}^{-1}\right)$ were calculated for the three adsorbents from the slopes and intercepts of the graphs between $\log \left(q_{e}-q_{t}\right)$ versus $t$. The pseudo first order kinetics denotes that the rate of occupation of adsorption site is directly proportional to the number of unoccupied sites.Moreover, the plot between $t / q_{t}$ versus $t$ for the three adsorbents showed excellent fit to the pseudo-second-order equation. $\mathrm{K}_{2}\left(\mathrm{~g} . \mathrm{mg}^{-1} \mathrm{~min}^{-1}\right.$ ) value from second-order kinetics is quite same for all the three adsorbents with $\mathrm{R}^{2}$ value 0.999 . It can thus be concluded that the reaction has followed a pseudo-second-order mechanism and not a pseudo-first-order mechanism.

\section{Conclusion}

Following conclusions were drawn depending on the results of the experimental studies:

Silver nanoparticles obtained from the leaf extracts of basil (O. sanctum) and neem (A. indica) was supported by the TEM and SEM images which showed spherical shaped AgNP with size around $50 \mathrm{~nm}$.

FTIR studies revealed the presence of alkane, amide, free alcohol, hydroxyl group, aromatic ring, aldehyde, carbonyl group, carboxyl group and alkene present in the sample.

The percentage dye removal was maximum for adsorbent made of basil plant. The statistics of removal of dye are $99.4 \%$ for silver nanocomposite made of basil leaf (O. sanctum), $98.1 \%$ for silver nanocomposite made of neem leaf (A. indica) and $97.4 \%$ for soil.

The Langmuir isotherm model provided best fit to the equilibrium data obtained, which indicates a monolayer adsorption on the surface and a minimal interaction of adsorbate and adsorbent. The negative value of Gibb's free energy indicated the spontaneous nature of the adsorption process.

Thus it can be concluded from the study that silver nanocomposite from different sources can be considered as a cost effective, eco-friendly and less energy consuming process for removal of hazardous dyes from the aqueous effluents. 


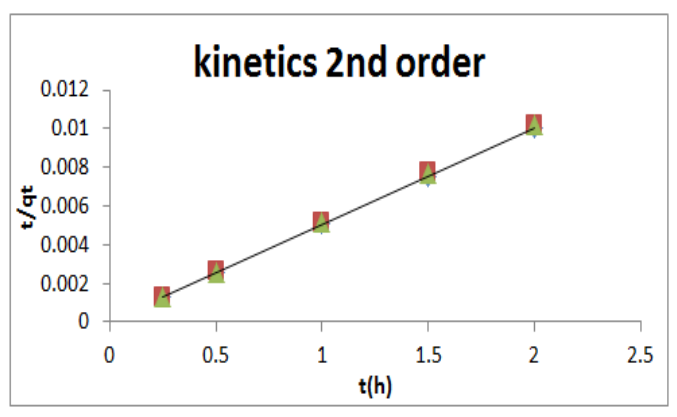

Figure 9. Ho-McKay's pseudo-second order curve.

\section{References}

1. A. Saeed, M. Sharif, M. Iqbal, "Application potential of grapefruit peel as dye sorbent: kinetics, equilibrium and mechanism of crystal violet adsorption". J. Hazard. Mater. (2010) 179:564-572.

2. A.R. Khataee, G. Dehghan, M. Zarei, E. Ebadi, M. Pourhassan, "Neural network modeling of biotreatment of triphenylmethane dye solution by a green microalgae", Chem. Eng. Res. Des. 89 (2011) 172-178.

3. B. Sadhegi, F. Gholamhoseinpoor, "A study on the stability and green synthesis of silver using Ziziphora tenuior (Zt) extract at room temperature", SpectrochimicaActa Part A : Molecular and Biomolecular spectroscopy 134 (2015) 310-315.

4. C. Namasivayam, R. Radhika, S. Suba, "Uptake of dyes by a promising locally available agricultural solid waste: coir pith". Waste Manag (2001b) 21:381-387.

5. C.J. Pandian, R. Palanivel, S. Dhananasekaran, "Green synthesis of nickel nanoparticles using Ocimum sactum and their application in dye and pollutant adsorption", Chinese journal of Chemical engineering 23(2015) 13071315 .

6. D.A. Kumar, V. Palanichamy, S.M. Roopan, "Green synthesis of silver nanoparticles using Alternanthera dentata leaf extract at room temperature and their antimicrobial property", SpectrochimicaActa Part A : Molecular and Biomolecular spectroscopy 127 (2014) 168-171.

7. E. M. Evangelin Femila, R. Srimathi, D. Charumathi, "Removal of Malachite Green using Silver nanoparticles via adsorption and chemical degradation", International journal of pharmacy and pharmaceutical science.

8. F. Mouxhg, L. Qingbiao, S.Daohua, L. Yinghua, H. Ning, D.Xu, et al. "Rapid preparation process of silver nanoparticles by bioreduction and their characterization". Chin. J. Chem. Eng. (2006);114-117.

9. G.M. Sulaiman, A.B. Mohammad, "Green synthesis, antimicrobial and cytotoxic effects of silver nanoparticles using Eucalyptus chapmaniana leaves extract". Asian Pac. J. Trop. Biomed. (2013) 3(1):58-63.

10.H.M.F. Freundlich (1906) Over the adsorption in solution. J PhysChem 57:385-471.

11.I. Langmuir (1916) "The constitution and fundamental properties of solids and liquids". J. Am. Chem. Soc. 38:2221-2295.

12. K. Natarajan, S. Selvary, R.V. Murty, "Microbial production of silver nanoparticles". Dig. J. Nanomater. Bios. (2010) 5:135-140.

13.M.A. Hossain, M. Kumita, Y. Michigami, S. Mori, "Kinetics of Cr (VI), adsorption on used black tea leaves", J.Chem. Eng...Jpn. 38 (6) (2005) 402-406.

14.M.B. Gholivand, Y. Yamini, M. Dayeni, S. Seidi, E. Tahmasebi, "Absorptive removal of alizarin red-S and alizarin yellow CG from aqueous solutions using polypyrrole - coated magnetic nanoparticles", Journal of Environment and Chemical Engineering 3 (2015) 529-540.

15.M.G. Moghaddam, R.H. Dabanlou, "Plant mediated green synthesis and antibacterial activity of silver nanoparticle using Crataegusdouglasii fruit extract", Journal of Industrial and Engineering Chemistry 20(2014) 739-744.

16.M.K. Satapathy, P. Banerjee, "Plant-mediated synthesis of silver-nanocomposite as a novel azodye adsorbent", ApplNanosci, 5 (1) (2013) 1-9. 
17.P. Jolly, K. Manas, Dhananjay K. Deshmukh, "Removal of methyl orange by activated carbon modified by silver nanoparticles", Appl. Water Sci, 3(2013) 367-374.

18.P.D. Saha, S. Chakraborty,S. Chowdhury, "Batch and continuous(fixed bed column) biosorption of crystal violet by Artocarpus heterophyllus (jackfruit) leaf powder", Colloid surf. B 92(2012) 262-270.

19.P.Kumar, M. Govindraju, S. Senthamilselvi, K. Premkumar, "Photocatalytic degradation of methyl orange dye using silver (Ag) nanoparticles synthesized from Ulva lactuca”, Colloids and Surfaces B: Biointerfaces 103 (2013) 658-661.

20.Q. Sun, X. Kai, J. Li, M. Zheng, Z. Chen, C.P. Yu, "Green synthesis of silver nanoparticles using tea leaf extract and evaluation of their stability and antibacterial property", Colloids and surfaces A: Physicochemical and Engineering aspects 444 (2014) 226-231.

21.R. Ahmad, "Studies on adsorption of crystal violet dye from aqueous solution onto Coniferous pinus bark powder (CPBP)". J Hazard Mater (2009) 171:767-773.

22.R. Mariselvam, A.J.A. Ranjitsingh, A.U.R. Nanthini, K. Kalirajan, C. Padmalatha, P.M. Selvakumar, "Green synthesis of silver nanoparticles from the extract of inflorescence of Cocos nucifera for enhanced antibacterial activity", SpectrochimicaActa Part A : Molecular and Biomolecular spectroscopy 129 (2014) 537-541.

23.S. Chakraborty, S. Chowdhury, P.D. Saha, "Adsorption of crystal violet from aqueous solution onto NaOHmodified rice husk". CarbohydrPolym (2011) 84:1533-154.

24.S. Chowdhury, P. Saha "Sea shell powder as a new adsorbent to remove Basic Green 4 (Malachite Green) from aqueous solutions: equilibrium, kinetic and thermodynamic studies". Chem Eng J (2010) 164:168-177.

25.S. Patra, S. Mukherjee, A.K. Barui, A. Ganguli, B. Sridhar, C.R. Patra, "Green Synthesis, Characterzation of gold and silver nanoparticles and their potential application for cancer therapeutics", Material Science and Engineering C 53 (2015) 298-309.

26.S. Prabhu, E.K. Poulose, "Silver nanoparticles: mechanism of antimicrobial action, synthesis, medical applications, and toxicity effects". Int Nano Lett (2012) 2:32-42.

27.S. Saha , D. Chattopadhyay, K. Acharya , "Preparation of silver nanoparticles by bioreduction using Nigrosporaoryzae culture filtrate and its antimicrobial activity". Dig J Nanometer Bios 2011;6:1519-28.

28.S. Senthilkumaar, P. Kalaamani, C.V. Subburaam, "Liquid phase adsorption of crystal violet onto activated carbons derived from male flowers of coconut". J Hazard Mater (2006) 136:800-808.

29.S. Zinadini, A.A. Zinatizadeh, M. Rahimi, V, Vatanpour, H. Zangeneh, M. Beygzadeh, "Novel high flux antifouling nanofiltration membranes for dye removal containing carboxymethyl chitosan coated Fe3O4 nanoparticles", Desalination 349 (2014) 145-154.

30.S.M. Pourmortazavi, M. Taghdiri,V. Makari, M.R. Nasrabadi, "Procedure optimization for green synthesis of silver nanoparticles by aqueous extract of Eucalyptus oleosa", SpectrochimicaActa Part A : Molecular and Biomolecular spectroscopy 136 (2015) 1249-1254.

31.V. Dhand, L. Soumya, S. Bharadwaj,S. Chakra, D. Bhatt, B. Sreedhar, "Green synthesis of silver nanoparticles usingCoffea Arabica seed extract and its antibacterial activities", Material Science and Engineering C 58 (2016) $36-53$.

32.V. Kathiravan, S. Ravi, S. Ashokkumar, S. Velmurugan, K. Elumalai, C.P. Khatiwada, "Green synthesis of silver nanoparticles using Croton sparsiflorus morong leaf extract and their antibacterial and antifungal activities", SpectrochimicaActa Part A : Molecular and Biomolecular spectroscopy 139 (2015) 200-205.

33.X.S. Wang, X. Liu, L.Wen, Y.Zhou, Z. Li, "Comparison of basic dye crystal violet from aqueous solution by lowcost biosorbents". Sep Sci.Technol. (2008) 43:3712-3731.

34.Y.S. Ho, G. McKay(1999) "Pseudo-second-order model for sorption processes". Proc.B iochem. 34:451-46 